www.jmscr.igmpublication.org

Impact Factor 3.79

Index Copernicus Value: 5.88

ISSN (e)-2347-176x ISSN (p) 2455-0450

crossref DOI: _http://dx.doi.org/10.18535/jmscr/v4i02.70

Journal Of Medical Science And Clinical Research

IGM Publication

An official Publication of IGM Publication

\title{
Recurrent Gastrointestinal Tract infections and Recurrent Respiratory Tract Infections Complicating the Severe Acute Malnutrition:-A Case- Control Study
}

Authors

\begin{abstract}
Dr Dipendra Sharma ${ }^{1}$, Dr Naresh Kumar Meena ${ }^{2}$, Dr Ankur Jain ${ }^{3}$, Dr R.K. Gulati ${ }^{4}$
${ }^{1}$ MD Pediatrics, Govt. Medical College Kota, Rajasthan, India

${ }^{2}$ Senior Resident, MD Pediatrics, Department of Pediatrics, Govt. Medical College Kota, Rajasthan, India

${ }^{3}$ Assistant Professor, Dept of Pediatrics, J.K.Lone Hospital, Govt. Medical College Kota, Rajasthan, India

${ }^{4}$ Senior Professor and Head of Department of Pediatrisc, Govt. Medical College Kota, Rajasthan, India
\end{abstract}

\begin{abstract}
INTRODUCTION:- Severe Acute Malnutrition affects nearly twenty million under five children, and contributes to one million child deaths yearly. The mortality rate of children with complicated SAM that receive treatment in inpatient set ups has remained unacceptably high. Such high mortality in inpatient units has been attributed to co-morbidities such as infections and micronutrient deficiencies. There is a lack of systematic reporting of clinical and laboratory data taken on admission or during hospital stay to identify baseline risk factors that allow comparative studies of the burden, spectrum and outcome of co-morbidities of severe malnutrition. Here we present a description of co-morbid findings in children admitted to a tertiary level hospital in central India.
\end{abstract}

OBJECTIVE: To determine the co-morbid conditions (Recurrent Gastrointestinal and Recurrent respiratory tract infections) associated with severe acute malnutrition.

METHODS: The present study was conducted at the Department of Paediatrics, Government Medical College, Kota (Rajasthan) for a period of one year from 1 January 2014 to 31 December 2014. A total number of 121 cases and 121 controls were admitted during the study period.

RESULTS:-Recurrent Gastrointestinal Tract Infection were found in 71 (58.68\%) cases and in 16 (13.22\%) controls difference was statistically significant, $p$ value $<0.0001$, OR=9.3. Recurrent Respiratory Infections were found in $52(42.97 \%)$ cases and in 22 (18.18\%) controls difference was statistically significant $p$ value < $0.0001, O R=3.3$.

CONCLUSION:-Recurrent Gastrointestinal Tract Infections (Diarrhoea) and Recurrent Respiratory Infections are significant risk factors for Severe acute malnutrition. This should be prevented by integrated health package (Various health programmes are already functional in India by government e.g. ICDS, Anganwadi scheme, RBSK, Malnutrition Treatment Center).

\section{INTRODUCTION}

Malnutrition is a major public health problem throughout the developing world and is an underlying factor in over $50 \%$ of the $10-11$ million children under 5 years of age who die each year of preventable causes ${ }^{(1)}$. 
Malnutrition in children is widely prevalent in developing countries including India more than $33 \%$ of deaths in 0-5 years are associated with malnutrition. Severe acute malnutrition (SAM) is a unique type of severe malnutrition and is different from severe underweight and severe stunting ${ }^{(2)}$.

According to national family health survey III (NFHS-3, 2005-06) 43\% children under age of five years are underweight (low weight for age). $48 \%$ children under five are stunted (low height for age). $20 \%$ children under five years of age are wasted (low weight for height) $6.4 \%$ of these children are severely wasted (<-3SD). Since 'wasting' denotes acute malnutrition, these children are said to have severe acute malnutrition or SAM. Median case fatality rate is approximately $23.5 \%$.This can be brought down to 7 to $10 \%$ by standard management protocols, that is why it is very important to identify severe acute malnutrition and managing appropriately ${ }^{(3)}$. Malnutrition in children is widely prevalent in developing countries and has been responsible for $60 \%$ of the 10.9 million deaths annually among children less than 5 years. Over $2 / 3^{\text {rd }}$ of these deaths which are often associated with inappropriate feeding practices occurred during 1st year of life ${ }^{(4)}$.

Severe acute malnutrition is defined (according to WHO Guideline) as weight for height less than 3SD and/or visible severe wasting and/or edema of both feet (excluding other causes of edema), mid arm circumference less than $11.5 \mathrm{~cm}$ (in infant more than 6 months of age) ${ }^{(3)}$.

Severe acute malnutrition is both a medical and social disorder. The medical problem is due to social problem at home. Lack of exclusive breast feeding, late introduction of complementary feeds, feeding diluted feeds containing less nutrients, repeated enteric infection, respiratory tract infections, ignorance, poverty are the risk factors for severe acute malnutrition. Lack of birth spacing, lack of maternal nutrition during lactation, high birth rate, low birth weight, prelacteal feeds, early and late weaning are other additional factors for severe acute malnutrition ${ }^{(4)}$.
Severely malnourished children have infective complications like diarrhoea with dehydration, acute lower respiratory infection, tuberculosis, candidiasis, and meningitis, non infective complications like edema, extensive skin lesions, keratomalacia, anaemia, hypothermia, jaundice, and hypoglycaemia.

Historically, the most severe forms of malnutrition, marasmus (nonedematous

malnutrition with severe wasting) and kwashiorkor (edematous malnutrition), were considered distinct disorders. Nonedematous malnutrition was believed to result primarily from inadequate energy intake or inadequate intakes of both energy and protein, whereas edematous malnutrition was believed to result primarily from inadequate protein intake. A third disorder, marasmic kwashiorkor, has features of both disorders (wasting and edema). The 3 conditions have distinct clinical and metabolic features, but they also have a number of overlapping features. A low plasma albumin concentration, often believed to be a manifestation of edematous malnutrition, is common in children with both edematous and nonedematous malnutrition $^{(5)}$. Nonedematous malnutrition (marasmus) is characterized by failure to gain weight and irritability, followed by weight loss and listlessness until emaciation results. The skin loses turgor and becomes wrinkled and loose as subcutaneous fat disappears. Loss of fat from the sucking pads of the cheeks often occurs late in the course of the disease thus, the infant's face may retain a relatively normal appearance compared with the rest of the body, but this too, eventually becomes shrunken and wizened. Infants are often constipated, but they can have starvation diarrhoea, with frequent small stools containing mucus. The abdomen may be distended or flat, with the intestinal pattern readily visible. There is muscle atrophy and resultant hypotonia. As the condition progresses, the temperature usually becomes subnormal and the pulse slows ${ }^{(5)}$.

Edematous malnutrition (kwashiorkor) can occur initially as vague manifestations that include lethargy, apathy, and/or irritability. When 
kwashiorkor is advanced, there is lack of growth, lack of stamina, loss of muscle tissue, increased susceptibility to infections, vomiting, diarrhea, anorexia, flabby subcutaneous tissues, and edema. The edema usually develops early and can mask the failure to gain weight. It is often present in internal organs before it is recognized in the face and limbs. Liver enlargement can occur early or late in the course of disease. Dermatitis is common, with darkening of the skin in irritated areas, but in contrast to pellagra not in areas exposed to sunlight. Depigmentation can occur after desquamation in these areas, or it may be generalized. The hair is sparse and thin, and in dark haired children, it can become streaky red or gray. Eventually, there is stupor, coma, and $\operatorname{death}^{(5)}$.

\section{MATERIAL AND METHOD}

Cases- Children between 6 month to 5 yrs with Wt-for-Ht less than -3SD and/or visible severe wasting and/or edema of both feet and/or mid arm circumference less than $11.5 \mathrm{~cm}$ admitted to Department of Pediatrics Government Medical College Kota(Rajasthan).

Control- Children between 6 month to 5 yrs without severe acute malnutrition admitted for other medical problems to the Department of Pediatrics Government Medical College Kota (Rajasthan).

Inclusion criteria: Age: 6 month to 5 years, Wtfor-Ht less than -3SD and/or, Visible severe wasting and/or, Edema of both feet and/or, Mid arm circumference less than $11.5 \mathrm{~cm}$.

Exclusion criteria: Refusal of consent, Child less than 6 month and more than 5 yrs of age, Wt-forHt more than -3SD, Other causes of edema (e.g. Nephrotic syndrome),Unilateral edema, Associated systemic diseases (congenital heart disease, malabsorption, cerebral palsy, secondary malnutrition etc.

Procedure: The patients fulfilling the inclusion criteria were included in the study after obtaining informed consent. All of the following information is recorded Name and fathers name, address, age, sex, registration no., mother-child pair questionnaire for all possible risk factors, general physical examination, examination of vitals, detail anthropometry are noted, weight measured by digital weighing machine, height measured by stadiometer and mid arm circumference are measured by measuring tape (Shakirs tape) in both case and control.

\section{METHOD}

Study participants were children under the age of five, admitted to the Department of Pediatrics Govt. Medical College Kota (Rajasthan). All admissions with severe acute malnutrition (SAM) were analyzed during the study period until the duration period was attained. The cases were children admitted with SAM and the controls were children without malnutrition admitted for other medical problems, sample size were taken from total patients admitted during the period of 1 Jan. 2014 to 31 Dec. 2014.

The data were collected using structured questionnaire for all possible risk factors, knowledge and practice on nutrition from the immediate caregivers, which were usually the mothers, general physical examination, examination of vitals, detail anthropometry are noted, weight measured by digital weighing machine, height measured by stadiometer and mid arm circumference are measured by measuring tape (Shakirs tape) in both case and control. Data were entered and analyzed by standard statistical methods.

\section{RESULTS}

The present study was conducted at the Department of Pediatrics, Government Medical College, Kota for a period of one year from 1 January 2014 to 31 December 2014. A total number of 121 cases and 121 controls were admitted during the study period. The following tables and figures illustrate the results in detail. The results obtained were analyzed 
Table 1: Sex wise distribution $(\mathrm{N}=121)$

\begin{tabular}{|l|c|c|}
\hline & CASE & CONTROL \\
\hline Male & $39(32 \%)$ & $70(58 \%)$ \\
\hline Female & $82(68 \%)$ & $51(42 \%)$ \\
\hline TOTAL & 121 & 121 \\
\hline
\end{tabular}

Table-2. Age wise distribution of patients (Cases and controls) $(\mathrm{N}=121)$

\begin{tabular}{|l|l|l|l|l|l|l|}
\hline Age group & $\begin{array}{l}0-12 \\
\text { month }\end{array}$ & $\begin{array}{l}13-24 \\
\text { month }\end{array}$ & $\begin{array}{l}25-36 \\
\text { month }\end{array}$ & $\begin{array}{l}37-48 \\
\text { month }\end{array}$ & $\begin{array}{l}49-60 \\
\text { month }\end{array}$ & Total \\
\hline CASE & $\begin{array}{l}45 \\
(37.1 \%)\end{array}$ & $\begin{array}{l}51 \\
(42.1 \%)\end{array}$ & $\begin{array}{l}20 \\
(15.7 \%)\end{array}$ & $3(2.4 \%)$ & $2(1.6 \%)$ & 121 \\
\hline CONTROL & $\begin{array}{l}40 \\
(33 \%)\end{array}$ & $\begin{array}{l}42 \\
(34.7 \%)\end{array}$ & $\begin{array}{l}20 \\
(16.5 \%)\end{array}$ & $12(9.9 \%)$ & $7(5.7 \%)$ & 121 \\
\hline
\end{tabular}

Table- 3. Recurrent enteric (GIT) infection ( $\mathrm{N}=121)$

\begin{tabular}{|l|l|l|l|}
\hline Recurrent enteric infection & Yes & No & Total \\
\hline Case & $71(58.68 \%)$ & $50(41.32 \%)$ & 121 \\
\hline Control & $16(13.22 \%)$ & $105(86.78 \%)$ & 121 \\
\hline
\end{tabular}

Recurrent Enteric infection was seen in $58.68 \%$ cases and in $13.22 \%$ controls difference was statistically significant, $\mathrm{p}$ value $<0.0001, \mathrm{OR}=9.3$

Table 4. Respiratory infections $(\mathrm{N}=121)$

\begin{tabular}{|l|l|l|l|}
\hline Respiratory infections & Yes & No & Total \\
\hline Case & $52(42.97 \%)$ & $69(57.03 \%)$ & 121 \\
\hline Control & $22(18.18 \%)$ & $99(81.82 \%)$ & 121 \\
\hline
\end{tabular}

Recurrent Respiratory infections was seen in $42.97 \%$ cases and in $18.18 \%$ controls difference was statistically significant $\mathrm{p}$ value $<0.0001, \mathrm{OR}=3.3$

\section{DISCUSSION}

Total 121 Case were analysed, $86 \%$ of the admitted children in the study group were between 6-24 months of age; $51 \%$ of these children were in the age group of 6-12 months and $35 \%$ of these children were in the age group of 13-24 months.

In present study Recurrent enteric infection was seen in $58.68 \%$ cases and in $13.22 \%$ controls difference was statistically significant, $\mathrm{p}$ value $=$ $<0.0001$, OR=9.3 which is supported by a study done by Ghulam Shabir Laghari, Muhammad Akbar et al in 2013 showed that chronic recurrent diarrhoea is a major risk factor for SAM was present in $61 \%$ cases $^{(79)}$.
A study done by Rakesh Kumar, Jyoti Singh et al in Diarrhea were found to be the most common comorbid disease associated with SAM. 54\% SAM children had diarrhea ${ }^{(82)}$ which supports the present study. A study done by Nebiyu Dereje in 2014 showed There was evident that significant association between severe wasting and the morbidity status by diarrhea $(\mathrm{OR}=5.4$,$) and fever$ $(\mathrm{OR}=3.2)^{(83)}$. In a study done by Bahawaluddin Jamro, Shankar Lal et al in 2012 showed that recurrent diarrhea was seen in 120(44.4\%) cases $^{(79)}$, which is comparable to present study. 


\section{CONCLUSION}

Recurrent Gastrointestinal Tract Infections (Diarrhoea) and Recurrent Respiratory Infections are significant risk factors for Severe acute malnutrition. This should be prevented by integrated health package (Various health programmes are already functional in India by government e.g. ICDS, Anganwadi scheme, RBSK, Malnutrition Treatment Center).

\section{REFERENCE}

1. Steve Collins, Nicky Dent, Paul Binns, Paluku Bahwere, Kate Sadler, Alistair Hallam s Management of severe acute malnutrition in children Vol 368 December 2, 2006 p1992r ; 2008. p. 229.

2. Aneja S, Kumar P, Chaudhary N, Shah D, Facility Based Care of Sever Acute Malnutrition (SAM); Participant Manual ;2011 March; P1,

3. WHO-country office for India, NRHM.Facility based care of severe acute malnutrition. March $2011 ; 10-11$.

4. Soloman Amsalu, Zemene Tigabu. Risk factors for severe acute malnutrition in children under five, a case study.Ethiopia Journal of Health and Development. 2008; 22(1):21-25.

5. http://www.expertconsultbook.com/expert consult/b/book.do?method=display\&eid $=4$ -u1.0-B978-1-4377-0755-7...C2009-060010-6--TOP\&isbn=978-1-4377- 0755-7 $\&$ select Book $=$ true $\&$ decorator $=$ none $\&$ type $=$ about Page $\&$ show Premium Link For Basic $=$ true $\&$ has Premium Title $=$ false.

6. Ghulam Shabir Laghari, Muhammad Akbar, Abdul Hameed Radhan, Zahid Hussain The Analysis of Risk Factors in Severe Protein Energy Malnutrition in Order to know their Significance for Outcome in Children from 2 Months to 5
Years of Age JLUMHS MAY-AUGUST 2013; Vol 12: No. 02.

7. Rakesh kumar, Jyoti singh, Karan joshi, H.P.singh and Bijesh hospitalized children with severe acute malnutrition in rewa districtindian pediatrics august 5, 2013 [epub ahead of prints].

8. Nebiyu Dereje,Determinants of Severe Acute Malnutrition among under Five Children in Shashogo Woreda, Southern Ethiopia: A Community Based Matched Case Control Study International Journal of Research (IJR) Vol-1, Issue-6, July 2014 ISSN 2348-6848). 